\title{
Three-spined stickleback Gasterosteus aculeatus, as a possible paratenic host for salmonid nematodes in a subarctic lake
}

\section{Paola E. Braicovich, Jesper A. Kuhn, Per- Arne Amundsen \& David J. Marcogliese}

\section{Parasitology Research}

Founded as Zeitschrift für

Parasitenkunde

ISSN 0932-0113

Volume 115

Number 3

Parasitol Res (2016) 115:1335-1338

DOI 10.1007/s00436-015-4854-8

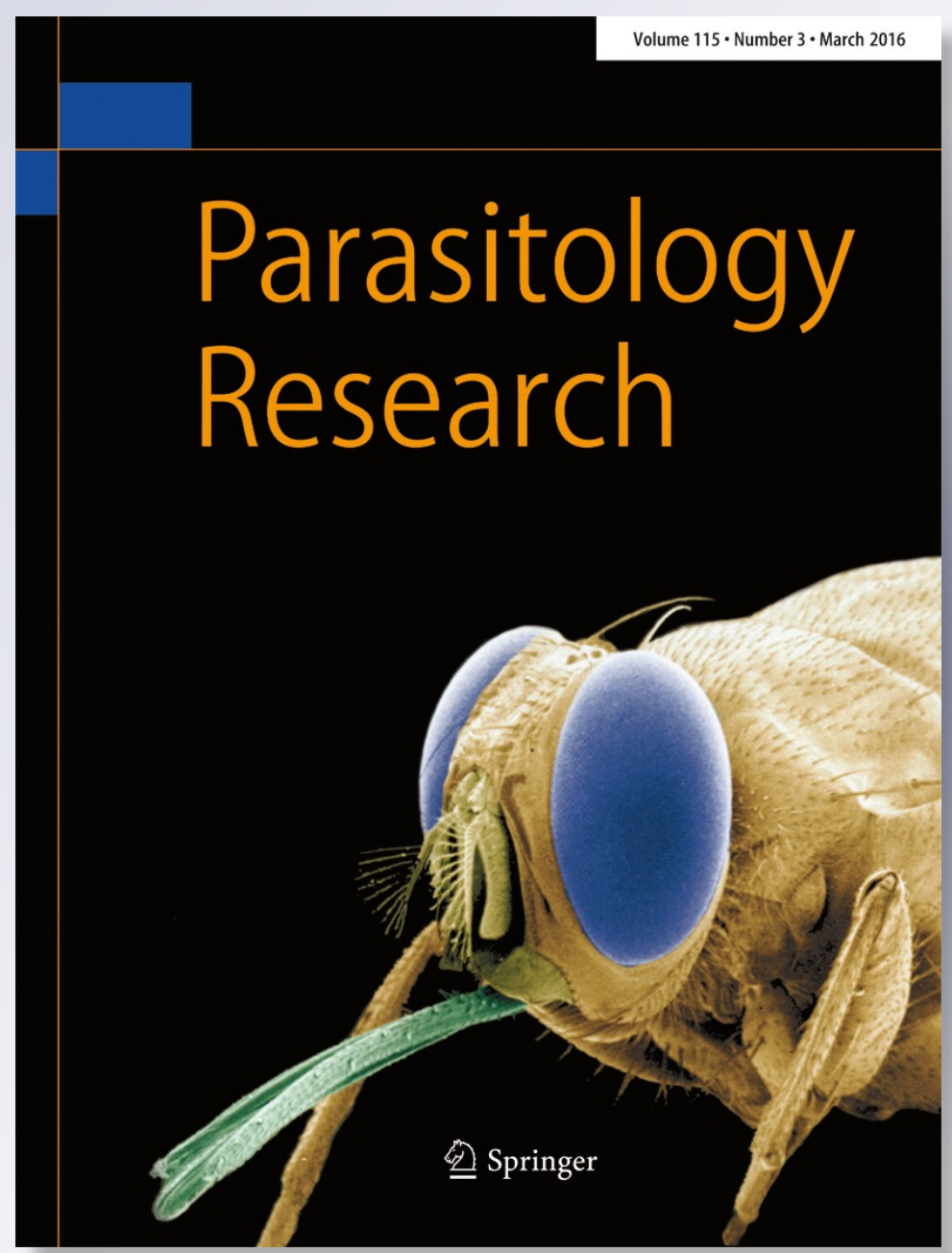

望 Springer 
Your article is protected by copyright and all rights are held exclusively by SpringerVerlag Berlin Heidelberg. This e-offprint is for personal use only and shall not be selfarchived in electronic repositories. If you wish to self-archive your article, please use the accepted manuscript version for posting on your own website. You may further deposit the accepted manuscript version in any repository, provided it is only made publicly available 12 months after official publication or later and provided acknowledgement is given to the original source of publication and a link is inserted to the published article on Springer's website. The link must be accompanied by the following text: "The final publication is available at link.springer.com". 


\title{
Three-spined stickleback Gasterosteus aculeatus, as a possible paratenic host for salmonid nematodes in a subarctic lake
}

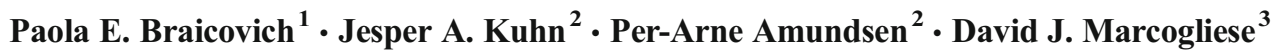

Received: 22 September 2015 / Accepted: 27 November 2015 / Published online: 9 December 2015

(C) Springer-Verlag Berlin Heidelberg 2015

\begin{abstract}
In Takvatn, a subarctic lake in northern Norway, 35 of 162 three-spined sticklebacks examined were infected with 106 specimens of third-stage larvae of Philonema oncorhynchi. The prevalence and mean intensity of $P$. oncorhynchi were $10 \%$ and 2.0 in 2013 and $24 \%$ and 3.0 in 2014, respectively. A single specimen of Cystidicola farionis was found in an additional sample. While the latter is considered an accidental infection, three-spined sticklebacks may function as paratenic hosts of $P$. oncorhynchi, potentially enhancing its transmission to salmonids due to their central role in the lacustrine food web of this subarctic lake.
\end{abstract}

Keywords Philonema sp. · Cystidicola sp. · Trophically transmitted parasites $\cdot$ Takvatn

Paola E. Braicovich

braicovi@mdp.edu.ar

1 Laboratorio de Ictioparasitología, Instituto de Investigaciones Marinas y Costeras (IIMyC), Facultad de Ciencias Exactas y Naturales, Universidad Nacional de Mar del Plata-Consejo Nacional de Investigaciones Científicas y Técnicas (CONICET), Funes 3350, 7600 Mar del Plata, Argentina

2 Department of Arctic and Marine Biology, Faculty of Biosciences, Fisheries and Economics, UiT The Arctic University of Norway, 9037 Tromsø, Norway

3 Aquatic Contaminants Research Division, Water Science and Technology Directorate, Science and Technology Branch, Environment and Climate Change Canada, St. Lawrence Centre, 105 McGill, 7th Floor, Montreal, Quebec H2Y 2E7, Canada

\section{Introduction}

Parasites are usually highly host specific (Poulin et al. 2011). However, some species, especially nematodes, may be able to utilize alternative hosts, where the parasite shows no apparent growth or development (Bush et al. 2001; Parker et al. 2009). These hosts may serve as paratenic hosts, which transmit the parasite to the definitive host when consumed. Though they are not necessary for the development of the parasite, they may enhance transmission between hosts by bridging ecological gaps and thereby potentially have an important role in the parasite's life cycle (Poulin and Valtonen 2001; Chubb et al. 2010). Here, we address the possible role of three-spined stickleback (Gasterosteus aculeatus) as a paratenic host for two salmonid nematodes in subarctic lacustrine fish communities.

Three-spined stickleback and Arctic charr (Salvelinus alpinus) are the main planktivorous vertebrates in Takvatn, a subarctic lake in northern Norway (Amundsen et al. 2009). Together with brown trout (Salmo trutta), these species are the only components of the fish community in the lake. Threespined sticklebacks have been found mainly in pelagic and littoral zones (Klemetsen et al. 2002) and are well-known potential intermediate hosts of trophically transmitted salmonid parasites in Takvatn (Amundsen et al. 2013; Kuhn et al. 2015).

The introduction of Arctic charr into Takvatn in 1930 (Amundsen et al. 2007) and three-spined sticklebacks in 1950 (Jørgensen and Klemetsen 1995) dramatically altered the food web topology and introduced several new parasite species (Amundsen et al. 2009, 2013), resulting in a large increase in the number of trophic links (Amundsen et al. 2013). Specifically, the presence of the introduced threespined stickleback has enhanced the completion of the life 
cycles of several fish parasites that use copepods as intermediate hosts (Amundsen et al. 2013).

The nematode parasites Philonema oncorhynchi KuitunenEkbaum, 1933 and Cystidicola farionis Fischer, 1798, which are found in Takvatn, infect crustaceans as intermediate hosts and salmonids as final hosts (Platzer and Adams 1967; Giæver et al. 1991; Moravec 2013). However, although not previously demonstrated, paratenic hosts may be involved in the circulation of these parasites in the environment (Moravec 2013). The present study explores the possible role of three-spined sticklebacks as paratenic hosts for $P$. oncorhynchi and $C$. farionis in Takvatn.

\section{Materials and methods}

Takvatn is an oligotrophic lake situated at $69^{\circ} 07^{\prime} \mathrm{N}, 19^{\circ} 05^{\prime} \mathrm{E}$ in subarctic Norway, $214 \mathrm{~m}$ above sea level and with a surface area of $14.2 \mathrm{~km}^{2}$ and a maximum depth of $80 \mathrm{~m}$. As part of extensive parasitological research performed in Takvatn, 162 three-spined sticklebacks were screened for nematodes associated with the swim bladder in July $2013(N=30)$ and August $2014(N=132)$. An additional sample taken in July $2013(N=$ 18) was used for morphological measurements of a single specimen but excluded from the parasitological parameters as this sample was not further processed for nematodes. The fish were caught with bottom gillnets (mesh sizes 6-8 $\mathrm{mm}$ ) in the littoral zone at depths of 1-8 $\mathrm{m}$. They were transported to the laboratory and dissected for nematodes using a stereomicroscope. For morphological studies, the specimens were fixed either in $5 \%$ formalin solution or $70 \%$ ethanol. Identification of the larval nematodes was based on the morphological descriptions of Platzer and Adams (1967). Ko and Adams (1969). and Moravec (2013). Measurements are expressed in microns $(\mu \mathrm{m})$ as a mean followed by the range in parentheses. Voucher specimens were deposited in the collection of the Royal Ontario Museum (Nos. ROMIZ F617ROMIZ F619). Prevalence (the number of fish infected divided by the number of fish examined, expressed as a percentage) and mean intensity (number of individuals of a parasite taxon found in a sample of infected fish, divided by the number of hosts infected with this parasite) were calculated for each sample as defined by Bush et al. (1997).

\section{Results}

In total, 35 of 162 three-spined sticklebacks examined were infected with 106 third-stage larvae of $P$. oncorhynchi, located in the mesenteric tissue covering the swim bladder, while 1 fish of the 18 from July 2013 was found parasitized with one specimen of third-stage larvae of $C$. farionis also found in the mesenteric tissue. The prevalence and mean intensity $( \pm \mathrm{SD})$ of $P$. oncorhynchi were $10 \%$ and $2.0( \pm 1.0)$ in samples from 2013 and $24.2 \%$ and $3.0( \pm 4.0)$ in those from 2014, respectively.

The third-stage larvae of $P$. oncorhynchi were identified based on the filiform body with a conical head and tail, liplike structures at the buccal region, a long and well-developed glandular esophagus, and a finger-like projection at the end of the tail. Comparative measurements from published studies on the third-stage larvae of the species of Philonema infecting three-spine sticklebacks, copepods, and experimental fish are shown in Table 1.

Cystidicola farionis was identified by the oral opening surrounded by two small lateral projection-like pseudolabia, a well developed vestibule, a long esophagus distinctly divided into the anterior muscular and posterior glandular parts, and a conical tail with small terminal protuberance at its end. The morphological measurements are as follows: total length 3720 , maximum width 130 , vestibule length 77.5 , esophagus $29.3 \%$ of the total length divided into a muscular part (150 long) and a glandular part (940 long), and nerve ring 210 from anterior end and tail (95 long).

\section{Discussion}

The third-stage larvae of both $P$. oncorhynchi and $C$. farionis were found parasitizing three-spined sticklebacks from Takvatn. Only two species of Philonema are reported in Europe. P. oncorhynchi is only recorded from Artic charr, whereas Philonema sibiricum (Bauer, 1946) occurs almost exclusively in freshwater fishes of the subfamily Coregoninae. In Europe, C. farionis is the only species of the genus Cystidicola. It is common in fishes of the families Salmonidae and Osmeridae of which brown trout is the most frequent host (Moravec 2013). Both $P$. oncorhynchi and C. farionis parasitize the salmonids in Takvatn (Giæver et al. 1991; Knudsen et al. 2002; Amundsen et al. 2009, 2013).

Little is known regarding the participation of other fish acting as intermediate host of these nematodes. Experimental infections of Philonema agubernaculum Simon and Simon, 1936 in smelt (Osmerus mordax), the predominant fish prey of salmonids in Maine, suggest that smelt may participate in the life cycle of this parasite (Vik 1964). However, the occurrence of P. oncorhynchi in three-spined sticklebacks from Takvatn in the present study is the first natural record of larval stages of this parasite in fishes other than the definitive host, supporting the hypothesis that other hosts may be involved in its life cycle as suggested by Moravec (2013). All P. oncorhynchi specimens found in the present study were third-stage larvae, the same stage occurring in the copepod intermediate host. This suggests that three-spined stickleback 
Table 1 Comparative measurements (based on 10 specimens) of third-stage larvae of Philonema oncorhynchi from three-spined sticklebacks Gasterosteus aculeatus, from Takvatn and published studies

\begin{tabular}{|c|c|c|c|c|}
\hline & $\begin{array}{l}\text { P. oncorhynchi } \\
\text { third-stage larvae } \\
\text { from copepod Ko } \\
\text { and Adams (1969) }\end{array}$ & $\begin{array}{l}\text { P. oncorhynchi third-stage } \\
\text { larvae from Oncorhynchus } \\
\text { nerka (9-10 days) Platzer } \\
\text { and Adams (1967) }\end{array}$ & $\begin{array}{l}\text { P. sibiricum } \\
\text { third-stage } \\
\text { larvae (infective) } \\
\text { Moravec (2013) }\end{array}$ & $\begin{array}{l}\text { P. oncorhynchi } \\
\text { third-stage larvae } \\
\text { sticklebacks, } \\
\text { present study }\end{array}$ \\
\hline Total body length & $934(788-1038)$ & $975(909-1070)$ & $597-880$ & $1083(1033-1150)$ \\
\hline Body width & $13(11-15)$ & - & $11-19$ & $22(18-25)$ \\
\hline Nerve ring-anterior end & $85(70-100)$ & $91(91-108)$ & - & $108(75-120)$ \\
\hline Muscular esophagus length & $188(137-351)$ & $205(165-228)$ & $125-288$ & $210(188-263)$ \\
\hline Glandular esophagus length & $399(198-533)$ & $454(388-570)$ & $217-385$ & $392(378-413)$ \\
\hline Excretory pore-anterior end & $110(100-114)$ & - & $69-91$ & $133(103-145)$ \\
\hline Excretory pore-nerve ring & - & - & - & $26(23-33)$ \\
\hline Genital primordium length & $18(17-21)$ & - & - & $28^{\mathrm{a}}$ \\
\hline Genital primordium-tail & - & - & - & $251(225-275)$ \\
\hline Tail length & $126(98-131)$ & $105(74-125)$ & $57-82$ & $130(113-158)$ \\
\hline$\%$ esophagus/body length & $62.8(42.5-85.2)$ & $67.6(60.8-74.6)$ & $57.3-76.5$ & $55.6(51.8-58.7)$ \\
\hline
\end{tabular}

${ }^{\mathrm{a}}$ Measurement based on one specimen

may function as a paratenic host for P. oncorhynchi as no parasite development apparently occurs.

In Europe, $P$. oncorhynchi has been recorded only in $S$. alpinus, while outside Europe, it occurs mostly in anadromous salmonids (Moravec 2013). The introduction of Arctic charr in Takvatn facilitated the arrival of $P$. oncorhynchi, which depends on charr as its obligate host in this system and was otherwise unable to complete its life cycle in the presence solely of brown trout (Amundsen et al. 2013). The subsequent introduction of stickleback formed a new intermediate size class in the pelagic zone of the lake, increasing predation on crustacean zooplankton (Amundsen et al. 2013). Thus, the larvae of $P$. oncorhynchi likely achieve greater host-finding success by also infecting three-spined sticklebacks, which then are preyed upon by large-sized Arctic charr.

The relatively high prevalence and intensity of larval stages of $P$. oncorhynchi recorded in the present study suggest that the presence of three-spined sticklebacks may enhance the transmission of this nematode species through the food web by acting as paratenic hosts. Typically, infections of invertebrate intermediate hosts occur at extremely low levels, limiting opportunities for transmission (Marcogliese 1995). By making use of paratenic hosts, infective stages of parasites can persist longer and exploit new food web pathways in an ecosystem (Marcogliese 1995, 2007; Kvach and Skóra 2007; Ondračková et al. 2009).

In northern lakes, the two primary pathways of trophically transmitted parasites to fish are through benthic (mainly amphipods) and pelagic (mainly copepods) crustaceans (Knudsen 1995). The third-stage larvae of C. farionis develop into an infective stage in the intermediate host, benthic amphipods, and mature in a variety of salmonids in Europe, Asia, and North America (Smith and Lankester 1979; Moravec 2013). According to Moravec (2013). reports of $C$. farionis in fish other than the common salmonid definitive host represent facultative hosts acquiring the infection by accidental ingestion of the intermediate amphipod host. In Takvatn, Gammarus lacustris is the intermediate host of $C$. farionis as it is the only species of amphipod inhabiting the lake (Giæver et al. 1991). However, G. lacustris is not the main prey of three-spined sticklebacks (Jørgensen and Klemetsen 1995). which could account for the low levels of this nematode found in the present study. Indeed, the rare occurrence of this parasite suggests that it may simply be an accidental host, with a little effect on its overall transmission to salmonids.

In addition to providing new linkages for the food web in Takvatn (Amundsen et al. 2009, 2013). the infection of threespined sticklebacks with these nematodes raises the possibility that these fish might act as paratenic hosts in the parasite transmission to salmonids, in particular P. oncorhynchi. Given the low infection level of $C$. farionis, it is more likely that this represents an accidental infection. Also, it further highlights the significance of the three-spined stickleback introduction to Takvatn, its subsequent effect on the parasites of salmonids, and emphasizes the central role of three-spined stickleback in the food web of this subarctic lake (Amundsen et al. 2013).

Funding This work was partly funded by UiT The Arctic University of Norway and the Norwegian Research Council (NFR213610/F20) to PAA and a Natural Sciences and Engineering Research Council of Canada Visiting Fellowship to PEB. 


\section{References}

Amundsen P-A, Knudsen R, Klemetsen A (2007) Intraspecific competition and density dependence of food consumption and growth in Arctic charr. J Anim Ecol 76:149-158. doi:10.1111/j.1365-2656. 2006.01179.x

Amundsen P-A, Lafferty KD, Knudsen R, Primicerio R, Klemetsen A, Kuris AM (2009) Food web topology and parasites in the pelagic zone of a subarctic lake. J Anim Ecol 78:563-572. doi:10.1111/j. 1365-2656.2008.01518.x

Amundsen P-A, Lafferty KD, Knudsen R, Primicerio R, Kristoffersen R, Klemetsen A, Kuris AM (2013) New parasites and predators follow the introduction of two fish species to a subarctic lake: implications for food-web structure and functioning. Oecologia 171:993-1002. doi:10.1007/s00442-012-2461-2

Bush AO, Lafferty KD, Lotz JM, Shostak AW (1997) Parasitology meets ecology on its own terms: Margolis et al. revisited. J Parasitol 83: $575-583$

Bush AO, Fernández JC, Esch GW, Seed RJ (2001) Parasitism: the diversity and ecology of animal parasites. Cambridge University Press, Cambridge

Chubb JC, Ball MA, Parker GA (2010) Living in intermediate hosts: evolutionary adaptations in larval helminthes. Trends Parasitol 26: 93-102, doi:10.1016/j.pt.2009.11.008

Giæver AA, Klemetsen A, Halvorsen O (1991) Infection of Cystidicola farionis Fisher (Nematoda: Spiruridea) in the swimbladder of Arctic charr, Salvelinus alpinus (L.), from Takvatn, North Norway. Nordic J Freshw Res 66:63-71

Jørgensen L, Klemetsen A (1995) Food resource partitioning of Arctic charr, Salvelinus alpinus (L.) and three-spined stickleback, Gasterosteus aculeatus L., in the littoral zone of lake Takvatn in northern Norway. Ecol Freshw Fish 4:77-84. doi:10.1111/j.16000633.1995.tb00120.x

Klemetsen A, Amundsen P-A, Grotnes P-E, Knudsen R, Kristoffersen R, Svenning M-A (2002) Takvatn through 20 years: Long-term effects of an experimental mass removal of Arctic charr Salvelinus alpinus from a subarctic lake. Environ Biol Fish 64:39-47

Knudsen R (1995) Relationships between habitat, prey selection and parasite infection in Arctic charr (Salvelinus alpinus). Nordic J Freshw Res 71:333-344

Knudsen R, Amundsen P-A, Klemetsen A (2002) Parasite-induced host mortality: indirect evidence from a long-term study. Environ Biol Fish 64:257-265. doi:10.1023/A:1016058304762
Ko RC, Adams JR (1969) The development of Philonema oncorhynchi (Nematoda: Philometridae) in Cyclops bicuspidatus in relation to temperature. Can J Zool 47:307-312. doi:10.1139/z69-062

Kuhn JA, Kristoffersen R, Knudsen R, Jakobsen J, Marcogliese DJ, Locke SA, Primicerio R, Amundsen P-A (2015) Parasite communities of two three-spined stickleback populations in subarctic Norway-effects of a small spatial-scale host introduction. Parasitol Res 114:1327-1339. doi:10.1007/s00436-015-4309-2

Kvach Y, Skóra KE (2007) Metazoa parasites of the invasive round goby Apollonia melanostoma (Neogobius melanostomus) (Pallas) (Gobiidae: Osteichthyes) in the Gulf of Gdańsk, Baltic Sea, Poland: a comparison with the Black Sea. Parasitol Res 100:767774. doi:10.1007/s00436-006-0311-z

Marcogliese DJ (1995) The role of zooplankton in the transmission of helminth parasites to fish. Rev Fish Biol Fisher 5:336-371. doi:10. 1007/BF00043006

Marcogliese DJ (2007) Evolution of parasitic life in the ocean: paratenic hosts enhance lateral incorporation. Trends Parasitol 23:519-521. doi:10.1016/j.pt.2007.09.001

Moravec F (2013) Parasitic nematodes of freshwater fishes of Europe (revised), 2nd edn. Praha Academia, Prague

Ondračková M, Dávidová M, Blažek R, Gelnar M, Jurajda P (2009) The interaction between an introduced fish host and local parasite fauna: Neogobius kessleri in the middle Danube River. Parasitol Res 105: 201-208. doi:10.1007/s00436-009-1384-2

Parker GA, Ball MA, Chubb JC (2009) To grow or not to grow? Intermediate and paratenic hosts as helminth life cycle strategies. J Theor Biol 258:135-147. doi:10.1016/j.jtbi.2009.01.016

Platzer EG, Adams JR (1967) The life history of a dracunculid, Philonema oncorhynchus, in Oncorhynchus nerka. Can J Zool 45: $31-43$

Poulin R, Valtonen ET (2001) Interspecific associations among larval helminths in fish. Int J Parasitol 31:1589-1596. doi:10.1016/ S0020-7519(01)00276-4

Poulin R, Krasnov BR, Mouillot D (2011) Host specificity in phylogenetic and geographic space. Trends Parasitol 27:355-361. doi:10. 1016/j.pt.2011.05.003

Smith JD, Lankester MW (1979) Development of swim bladder nematodes (Cystidicola spp.) in their intermediate hosts. Can J Zool 57: 1736-1744. doi:10.1139/z79-225

Vik R (1964) Notes on the life history of Philonema agubernaculum Simon et Simon, 1936 (Nematoda). Can J Zool 42:511-512. doi: 10.1139/z64-043 